\title{
Laboratory assessment of rivaroxaban: a review
}

\author{
Meyer Michel Samama ${ }^{1,2^{*}}$, Geneviève Contant ${ }^{3}$, Theodore E Spiro ${ }^{4}$, Elisabeth Perzborn ${ }^{5}$, Lena Le Flem², \\ Céline Guinet $^{2}$, Yves Gourmelin ${ }^{3}$, Gabriele Rohde ${ }^{5}$ and Jean-Luc Martinoli ${ }^{3}$
}

\begin{abstract}
Research into new anticoagulants for preventing and treating thromboembolic disorders has focused on targeting single enzymes in the coagulation cascade, particularly Factor Xa and thrombin, inhibition of which greatly decreases thrombin generation. Based on the results of phase III clinical trials, rivaroxaban, a direct Factor Xa inhibitor, has been approved in many countries for the management of several thromboembolic disorders. Owing to its predictable pharmacokinetic and pharmacodynamic characteristics, fixed-dose regimens are used without the need for routine coagulation monitoring. In situations where assessment of rivaroxaban exposure may be helpful, anti-Factor Xa chromogenic assays (in tandem with standard calibration curves generated with the use of rivaroxaban calibrators and controls) could be used. It is important to note that test results will be affected by the timing of blood sampling after rivaroxaban intake. In addition, the anti-Factor Xa method measures the drug concentration and not the intensity of the drug's anticoagulant activity, and a higher than expected rivaroxaban plasma level does not necessarily indicate an increased risk of bleeding complications. Therefore, clinicians need to consider test results in relation to the pharmacokinetics of rivaroxaban and other patient risk factors associated with bleeding.
\end{abstract}

Keywords: Factor Xa, Laboratory assessment, Rivaroxaban

\section{Introduction}

Traditional anticoagulant agents such as vitamin $\mathrm{K}$ antagonists (VKAs), unfractionated heparin (UFH), low molecular weight heparins and fondaparinux have been widely used in the prevention and treatment of thromboembolic diseases. However, these agents are associated with limitations, such as the need for regular coagulation monitoring (VKAs and UFH) [1,2] or a parenteral route of administration (UFH, low molecular weight heparin and fondaparinux) [2]. These limitations have prompted the development of target-specific oral anticoagulants that directly inhibit single enzymes in the coagulation pathway, such as Factor Xa or thrombin. Two direct Factor Xa inhibitors (rivaroxaban [Xarelto ${ }^{\circ}$, Bayer Pharma AG and Janssen Pharmaceuticals, Inc.] and apixaban [Eliquis', Bristol-Myers Squibb and Pfizer EEIG]) and a direct thrombin inhibitor (dabigatran etexilate [Pradaxa ${ }^{\circ}$, Boehringer Ingelheim International

\footnotetext{
* Correspondence: meyermichel.samama@biomnis.com

${ }^{1}$ Hôtel-Dieu University Hospital, 1 place du Paris Notre-Dame, 75004 Paris

4ème, Paris, France

${ }^{2}$ Biomnis Laboratories R \& D, 78 avenue de Verdun, BP 110, 94200

Ivry-sur-Seine, Paris, France

Full list of author information is available at the end of the article
}

$\mathrm{GmbH}]$ ) are approved in many countries for the prevention of venous thromboembolism (VTE) after elective hip or knee replacement surgery in adults, and in the European Union (EU) and North America for the prevention of stroke and systemic embolism in adult patients with nonvalvular atrial fibrillation [3-8]. In addition, rivaroxaban is also approved in the EU and North America for the treatment of deep vein thrombosis (DVT) and pulmonary embolism, and prevention of recurrent DVT and pulmonary embolism in adults, and is now approved in the EU, in combination with antiplatelet agents, for the prevention of atherothrombotic events in adults who have acute coronary syndromes and elevated cardiac biomarkers $[3,4,9]$.

The mechanisms of action of anticoagulant agents have an important role in the prolongation of clotting time in tests such as the prothrombin time (PT) test. VKAs interfere with the rcarboxylation of glutamate residues in Factors II, VII, IX and X, with the result that the coagulant activity of these factors is diminished. Direct Factor Xa inhibitors limit thrombogenesis via selective inhibition of Factor Xa without requiring cofactors such as antithrombin [10]. Direct thrombin inhibitors target thrombin and, likewise, do not require cofactors 
such as antithrombin [11]. Both classes of anticoagulant agents have predictable, dose-dependent anticoagulant effects [12]. Rivaroxaban inhibits free Factor Xa and prothrombinase activity as well as clot-bound Factor Xa, thus effectively blocking thrombin generation [13]. Inhibition of Factor Xa activity by rivaroxaban is closely correlated to its plasma concentration. Anti-Factor Xa activity can be measured to indicate rivaroxaban exposure.

As with apixaban and dabigatran, rivaroxaban does not require routine coagulation monitoring or dose titration (unlike VKAs and UFH). However, a reliable laboratory assay that could measure exposure to rivaroxaban may be necessary or helpful in certain clinical circumstances (e.g. prior to urgent surgery, for perioperative management of those receiving rivaroxaban, for patients with thromboembolic or bleeding events, or for suspected overdose). Because rivaroxaban and other target-specific oral anticoagulants have different mechanisms of action from traditional anticoagulant agents, laboratory tests used for these traditional agents (such as PT/international normalised ratio [INR] or activated partial thromboplastin time) are not suitable for targetspecific oral anticoagulants [14]. This article will summarise the pharmacokinetics and pharmacodynamics of rivaroxaban and provide information and guidance on laboratory tests that can be used for the measurement of rivaroxaban in clinical practice.

\section{Pharmacokinetics and pharmacodynamics of rivaroxaban}

The oral bioavailability of rivaroxaban is $80-100 \%$ for the $10 \mathrm{mg}$ dose, irrespective of food intake $[3,15]$. Under fed conditions, rivaroxaban $10 \mathrm{mg}, 15 \mathrm{mg}$ and $20 \mathrm{mg}$ tablets demonstrate dose-proportional bioavailability. In a fasted state, rivaroxaban pharmacokinetics are approximately linear up to about $15 \mathrm{mg}$ once daily, and oral bioavailability is reduced to $66 \%$ after a $20 \mathrm{mg}$ tablet; at higher doses, bioavailability decreases as a result of poor solubility $[3,16]$. Food does not affect the area under the concentration-time curve or maximum plasma concentration $\left(C_{\max }\right)$ of the $10 \mathrm{mg}$ dose [3]. The administered oral dose of rivaroxaban is absorbed rapidly, with $\mathrm{C}_{\max }$ occurring 2-4 hours after tablet intake [15].
At total daily oral doses of rivaroxaban of 5-60 mg, $\mathrm{C}_{\max }$ ranges (mean values) from $40 \mu \mathrm{g} / \mathrm{l}$ to $400 \mu \mathrm{g} / \mathrm{l}$, and minimum plasma concentration $\left(\mathrm{C}_{\text {trough }}\right)$ (mean values) from $8 \mu \mathrm{g} / \mathrm{l}$ to $160 \mu \mathrm{g} / \mathrm{l}$ (data derived from phase II studies of rivaroxaban in patients undergoing hip replacement surgery, patients with DVT or patients with acute coronary syndrome; Table 1) [17-19].

No relevant accumulation occurs beyond steady state in healthy individuals [20]. Elimination of rivaroxaban from plasma occurs with a terminal half-life of 5-9 hours in young individuals $[3,20]$ and 11-13 hours in the elderly [3,21]. Rivaroxaban has a dual mode of elimination. Of the administered dose, approximately two-thirds undergoes metabolic degradation, half of which is eliminated renally and the other half by the hepatobiliary route. The final one-third of the administered dose undergoes direct renal excretion as unchanged active substance in the urine, mainly via active renal secretion. Rivaroxaban has no major or active circulating metabolites [3,22].

In phase I studies in healthy subjects $[15,20,23]$ and in phase II studies of patients undergoing major orthopaedic surgery [17] or those with acute coronary syndrome [18], rivaroxaban was found to have predictable, dosedependent pharmacokinetics. In addition, population modelling suggests that pharmacokinetic parameters are generally similar between different patient groups (i.e. VTE prevention and treatment of acute DVT) [19].

\section{Influence on coagulation assays Prothrombin time}

Rivaroxaban prolongs PT (measured in seconds or PT ratio) in a linear and concentration-dependent manner when using reagents sensitive to rivaroxaban, such as Neoplastin Plus ${ }^{\oplus}$ (Diagnostica Stago, Asnières-sur-Seine, France) or HemosIL RecombiPlasTin 2G (Instrumentation Laboratory, Bedford, MA, USA). However, results vary according to the thromboplastin reagent used, as shown by in vitro [13,24-26] and ex vivo studies in patients undergoing hip or knee replacement surgery (total daily doses of 5-60 mg) [17]. The concentration of rivaroxaban required to double $\mathrm{PT}$ in human plasma using Neoplastin Plus is $301 \mu \mathrm{g} / \mathrm{l}$ [13]. In contrast, the concentration of rivaroxaban required to double $\mathrm{PT}$ in

Table 1 Summary of pharmacokinetic characteristics of rivaroxaban at steady state based on phase II data

\begin{tabular}{|c|c|c|c|c|c|c|}
\hline \multirow[t]{2}{*}{ Parameter } & \multicolumn{6}{|c|}{ Rivaroxaban dose } \\
\hline & $2.5 \mathrm{mg} \mathrm{bid*}$ & $2.5 \mathrm{mg} \mathrm{bid}^{\#}$ & 5 mg bid* & 10 mg bid* & 20 mg bid* & $30 \mathrm{mg} \mathrm{bid}^{\ddagger}$ \\
\hline$\overline{A \cup C}(\mu \mathrm{g} \cdot \mathrm{h} / \mathrm{l})$ & 300 & 328 & 464 & 974 & 1764 & 6500 \\
\hline$C_{\max }(\mu \mathrm{g} / \mathrm{l})$ & 53 & 40 & 86 & 180 & 299 & 400 \\
\hline$C_{\text {trough }}(\mu \mathrm{g} / \mathrm{l})$ & 8 & 14 & 11 & 38 & 68 & 160 \\
\hline
\end{tabular}

*Data are mean values from an analysis of the ODIXa-HIP2 study [17]. "Data are median values from an analysis of the ATLAS ACS TIMI 46 study (subset of patients aged $<50$ years) [18]. ${ }^{\ddagger}$ Data are mean values from an analysis of the ODIXa-DVT study [19].

Abbreviations: $A U C$ area under the concentration-time curve, bid twice daily, $C_{\text {max }}$ maximum plasma concentration, $C_{\text {trough }}$ minimum plasma concentration. 
human plasma with Innovin ${ }^{\circledR}$ (Siemens HealthCare Diagnostics, Marburg, Germany) is $700 \mu \mathrm{g} / \mathrm{l}$ [24]. Neoplastin Plus can be used in a dilute PT test, which is more sensitive than the PT test [24]. As with the PT test, rivaroxaban results in a linear concentration-dependent prolongation of dilute $\mathrm{PT}$, with varying gradients of the concentration-effect relationships for different thromboplastin reagents, as shown by an in vitro study [24].

\section{Other coagulation assays}

Rivaroxaban prolongs clotting times concentrationdependently in the activated partial thromboplastin time [24], HepTest (Sekisui Diagnostics, Stamford, CT, USA [27]) $[15,20]$ and prothrombinase-induced clotting time (PiCT) test [24,26,28]. However, for the HepTest and $\mathrm{PiCT}$ test, there is a paradoxical shortening of clotting time at low rivaroxaban concentrations when bovine Factor Xa is used [24]. This effect is not seen with a shorter or no incubation period, when antithrombindepleted (immunodeficient) plasma (instead of plateletpoor plasma) is used [24,28], or when human Factor Xa is used (in the PiCT test only) [28]. Rivaroxaban also affects thrombin generation parameters (prolonging lag time and time to peak of thrombin generation) and decreases peak thrombin generation and endogenous thrombin potential $[24,29]$. There is a more pronounced effect on the initiation and propagation phases of thrombin generation than on the decay phase [30]. However, thrombin generation tests are not available in many clinical laboratories.

\section{Inhibition of Factor Xa activity}

Inhibition of Factor $\mathrm{Xa}$ and plasma rivaroxaban levels are closely correlated [20]. Therefore, assays (particularly chromogenic assays) that measure inhibition of Factor Xa activity can quantify rivaroxaban plasma concentrations [25,26,31-33]. These types of assay are able to measure a wide range of rivaroxaban concentrations (e.g. 20-500 $\mu \mathrm{g} / \mathrm{l}$ ) by use of a reference calibration curve for rivaroxaban spiked in plasma [31]. Standardisation of these assays to measure rivaroxaban involves the use of rivaroxaban calibrators and controls [33], and standardised assay kits are now commercially available for clinical use (e.g. BIOPHEN Factor X Chromogenic [Aniara, West Chester, OH, USA], $\mathrm{STA}^{\oplus}$ Liquid Anti-Xa and $\mathrm{STA}^{\oplus}$ rivaroxaban calibrator and control [Diagnostica Stago], Technochrom anti-Xa and Technoview rivaroxaban calibrator and control [Technoclone GmbH, Vienna, Austria]).

\section{Is prothrombin time suitable for measuring rivaroxaban?}

The variability in responses between thromboplastin reagents used in the PT test is too large when the results are expressed in seconds for samples containing the same concentrations of rivaroxaban $[24,34]$. This variation is caused by different sensitivities of the reagents to rivaroxaban [34], possibly caused by interactions between Factor Xa inhibitors and phospholipids in thromboplastin reagents [35]. This variability is not corrected by conversion of PT to INR values [24]. The INR has been developed specifically for monitoring anticoagulation with VKAs [1] and, therefore, should not be used for rivaroxaban. Moreover, conversion of PT to INR values can increase the variability [36].

Normal PT can indicate intact haemostatic function [37]. An in vitro study showed that reduction of the variability in PT results across thromboplastin reagents by use of an international sensitivity index valid for rivaroxaban is feasible [38]. In addition, a modified PT test could be potentially useful [24]. Recently, a study assessing rivaroxaban effect with Simplastin ${ }^{\circledR}$ Excel $S$ reagent (Tcoag Ireland, County Wicklow, Ireland) suggested that it might have a similar effect to VKAs [39]. Results were reported in a field trial of 18 centres that compared PT results from different laboratories using different local reagents versus one central reagent and local instruments. This trial reported inter-laboratory variation in mean PT values that was significantly reduced by use of a centrally provided PT reagent $\left(\mathrm{STA}^{\bullet}\right.$ Néoplastine CI Plus [Diagnostica Stago]) and when results were expressed as rivaroxaban concentrations ( $\mu \mathrm{g} / \mathrm{l})$ [40]. This method may be sensitive enough to measure peak rivaroxaban plasma concentrations that would occur after currently approved therapeutic doses, i.e. provide a qualitative confirmation of the presence of rivaroxaban [37]. However, it lacks precision, particularly at low rivaroxaban concentrations and is, therefore, not suitable for measuring rivaroxaban levels in blood samples taken near the time of $C_{\text {trough }}$ [37]. In addition, specific calibrators for use with the PT test are not commercially available.

The effect of rivaroxaban (as with other target-specific oral anticoagulants) on PT is short-lived (e.g. minimal effect at 24 hours post-dosing [3]) and changes over time, whereas the effects of VKAs on PT last for several days $[1,20,21]$. In addition, the PT test, like other global clotting assays, is not specific for Factor $\mathrm{Xa}$ and can be influenced by many disease conditions, such as liver disease, some types of cancer and Hodgkin's disease [41-43].

\section{Are anti-Factor Xa chromogenic assays the preferred method for measuring rivaroxaban?}

Anti-Factor Xa chromogenic assays can accurately measure a wide range of rivaroxaban concentrations in plasma - i.e. give a quantitative measure of the rivaroxaban level - provided that a standard calibration curve is generated with rivaroxaban calibrators and controls $[33,44,45]$. A field trial of 23 centres has shown that anti-Factor Xa chromogenic assays, in conjunction with 
calibrators and controls for rivaroxaban, can measure rivaroxaban concentrations in plasma in the range of 20-660 $\mu \mathrm{g} / \mathrm{l}$ [33]. Furthermore, the mean rivaroxaban concentrations measured were in agreement with the expected values, even at the low rivaroxaban concentration when a modified STA ${ }^{\oplus}$ Rotachrom ${ }^{\circ}$ test (Diagnostica Stago) set-up was used. In this test, plasma samples were diluted to a ratio of 1:4 in Owren-Koller assay buffer to enable measurement of rivaroxaban concentrations $>100 \mu \mathrm{g} / \mathrm{l}$. Moreover, there was less variation among the different laboratories when using the centrally provided reagent compared with using local anti-Factor Xa reagents, particularly for the lowest rivaroxaban plasma concentration. The coefficients of variation at $20 \mu \mathrm{g} / \mathrm{l}$ reached $37.0 \%$ with local methods, compared with $19.1 \%$ with the centrally provided reagent; $13.7 \%$ versus $10.9 \%$ at $199 \mu \mathrm{g} / \mathrm{l}$ actual rivaroxaban value; and $14.1 \%$ versus $10.0 \%$ at $662 \mu \mathrm{g} / \mathrm{l}$ actual rivaroxaban value (1:3 diluted plasma). In addition, a Swiss study across nine laboratories showed that inter-laboratory precision of the chromogenic antiFactor Xa assay, Biophen Heparin 6 (Hyphen Biomed, Neuilly-sur-Oise, France), was satisfactory, with the coefficient of variation in the range of 2.6-10.5\% [45].

Another study measured rivaroxaban in ex vivo blood samples from patients who received rivaroxaban $10 \mathrm{mg}$ once daily for VTE prevention after hip or knee replacement surgery [44]. With the use of rivaroxaban calibrators and controls (set to enable measurement of plasma rivaroxaban $\geq 10 \mu \mathrm{g} / \mathrm{l}$ ) in this study, three chromogenic anti-Factor Xa methods were evaluated: one with the addition of exogenous antithrombin (Technochrom ${ }^{\odot}$ anti-Xa [AT+] [Technoclone, Vienna, Austria]) and two without the addition of antithrombin (COAMATIC ${ }^{\circledast}$ Heparin [Chromogenix, Milan, Italy]; and Technochrom ${ }^{\odot}$ anti-Xa, [Technoclone]). All of the assays showed a linear relationship between the optimal density of the chromogenic assays and rivaroxaban concentrations validated by high-performance liquid chromatography coupled with tandem mass spectrometry. However, the method in which antithrombin was added detected falsely high rivaroxaban levels [44]. These findings support the suitability of anti-Factor Xa assays (without the addition of antithrombin) in measuring rivaroxaban concentrations. Although anti-Factor Xa chromogenic assays differ in their sensitivity to rivaroxaban, mathematical modelling could decrease the variation between assays [32]. AntiFactor Xa chromogenic assay kits specifically developed for rivaroxaban calibrators and controls are now commercially available for clinical use.

\section{Interpretation of measured plasma levels}

An understanding of expected rivaroxaban plasma concentrations after therapeutic doses is important for the interpretation of measured results. The plasma levels of rivaroxaban in phase II studies are shown in Table 2 $[18,19,46]$.

In addition, data show that there is some interindividual variability in plasma rivaroxaban concentrations, but the clinical relevance of this variation has not been determined. In healthy individuals, approximate geometric coefficients of variation for $\mathrm{C}_{\max }$ are $16 \%$ after a $10 \mathrm{mg}$ dose, $36 \%$ after a $20 \mathrm{mg}$ dose [15] and 19\% after a $20 \mathrm{mg}$ twice-daily dose [20]. However, after hip replacement surgery, the geometric coefficients of variation of rivaroxaban at total daily doses of 5-20 mg are higher than in healthy individuals and in the range of 60-93\% for $\mathrm{C}_{\text {trough }}$ and $47-74 \%$ for $\mathrm{C}_{\max }$ [17].

Accumulating data indicate that anti-Factor Xa chromogenic assays (with use of rivaroxaban calibrators and controls) are able to measure a wide range of rivaroxaban concentrations encompassing the entire range after therapeutic dosing $[1,2,24]$. The timing of blood sampling after tablet intake is important because levels of rivaroxaban change markedly over time owing to the pharmacokinetics of the drug (e.g. levels of rivaroxaban will differ greatly 2-4 hours versus 24 hours after dosing).

\section{Conclusions}

Unlike VKAs, the target-specific oral anticoagulants (such as rivaroxaban, dabigatran, apixaban and edoxaban) are

Table 2 Rivaroxaban plasma concentrations after therapeutic doses based on phase II data and simulated virtual data

\begin{tabular}{llll}
\hline Dose & Clinical setting & $\boldsymbol{C}_{\text {trough }}(\boldsymbol{\mu g} / \mathbf{l})$ & $\boldsymbol{C}_{\max }(\boldsymbol{\mu g} / \mathbf{l})$ \\
\hline $2.5 \mathrm{mg}$ bid & Acute coronary syndrome & $16(6-34)^{*}$ & $44(28-66)^{*}$ \\
$10 \mathrm{mg} \mathrm{od}$ & VTE prevention after total hip replacement & $9(1-38)^{\#}$ & $125(91-196)^{\#}$ \\
$15 \mathrm{mg} \mathrm{od}$ & Stroke prevention in patients with AF $(\mathrm{CrCl} \leq 50 \mathrm{ml} / \mathrm{min})$ & $57(18-136)^{\ddagger}$ & $229(178-313)^{\ddagger}$ \\
$20 \mathrm{mg} \mathrm{od}$ & DVT treatment (continued treatment) & $26(6-87)^{\S}$ & $270(189-419)^{\S}$ \\
$20 \mathrm{mg} \mathrm{od}$ & Stroke prevention in patients with AF $(\mathrm{CrCl}>50 \mathrm{ml} / \mathrm{min})$ & $44(12-137)^{\ddagger}$ & $249(184-343)^{\ddagger}$ \\
\hline
\end{tabular}

*Estimated parameters at steady state - median values (5th-95th percentile range) [18]. "Estimated parameters at steady state - median values (5th-95th percentile range) in patients undergoing hip replacement surgery [46]. ${ }^{\ddagger}$ Estimated parameters at steady state - geometric means (5th-95th percentile range) in stroke prevention in patients with AF (Bayer HealthCare Pharmaceuticals and Janssen Research \& Development, LLC: data on file). ${ }^{5}$ Estimated parameters at steady state - geometric means (5th-95th percentile range) in phase II studies in the acute treatment of DVT [19].

Abbreviations: $A F$ atrial fibrillation, bid: twice daily, $C_{\max }$ maximum plasma concentration, $\mathrm{CrCl}$ creatinine clearance, $C_{\text {trough }}$ minimum plasma concentration, DVT deep vein thrombosis, od once daily, VTE venous thromboembolism. 
currently used in clinical practice at fixed doses without the need for routine coagulation monitoring [47]. The concentration of target-specific oral anticoagulants may potentially need to be measured in certain clinical situations [48], such as before urgent surgery, perioperative management, thromboembolic or bleeding events, or in cases of suspected overdose. The conventional PT/INR method has some important limitations. For measuring apixaban, anti-Factor Xa chromogenic assays are preferable to the PT test because they yield more accurate results [25]. Similarly, accumulating data indicate that the antiFactor Xa chromogenic assay is the most suitable assay for the quantitative assessment of rivaroxaban, provided rivaroxaban calibrators and controls are used, and results are expressed as rivaroxaban concentration $(\mu \mathrm{g} / \mathrm{l})$ [33]. If this method is not available or in an emergency situation, such as before urgent surgery, the PT assay (expressed in seconds) using a thromboplastin reagent sensitive to rivaroxaban may be useful to indicate whether the anticoagulant effect of rivaroxaban is present [3], provided that the patient's baseline PT is not abnormal. However, interpretation of the results should take into account the pharmacokinetic characteristics of rivaroxaban. A PT reagent has recently been found to have particularly high sensitivity to the effects of rivaroxaban, but no explanation has been proposed [39]. A point-of-care assay has been studied for the qualitative assessment of rivaroxaban in urine samples [49], which may be potentially useful in investigating treatment compliance, for example. However, this method needs further validation if it is to be used in clinical practice.

Practical considerations for the quantitative measurement of rivaroxaban using anti-Factor Xa chromogenic assays include the timing of blood sampling, interpretation of test results and standardisation of the assays. The timing of blood sampling in relation to the pharmacokinetic characteristics of rivaroxaban is important because it will directly influence the test results; for example, plasma levels of rivaroxaban will be high in the period 2-4 hours after drug administration compared with 12-24 hours after dosing. Therefore, an understanding of the expected time to $\mathrm{C}_{\max }$ and $\mathrm{C}_{\text {trough }}$ of rivaroxaban is important when interpreting test results. Another practical consideration is the interpretation of test results and potential clinical implications. It is important to note that the anti-Factor Xa method measures the drug concentration (quantitative assessment) and not the intensity of the drug's anticoagulant activity (qualitative assessment) [24], whereas coagulation assays used for monitoring the traditional anticoagulants, VKAs and UFH, indicate the intensity of anticoagulation [1,2]. In addition, a higher than expected plasma level does not necessarily indicate an increased risk of bleeding complications but could signal a need for closer surveillance for risk of bleeding.
Standardised anti-Factor Xa chromogenic assays with rivaroxaban calibrators and controls (e.g. BIOPHEN Factor X Chromogenic [Aniara], $\mathrm{STA}^{\circ}$ Liquid anti-Xa and $\mathrm{STA}^{\circ}$ rivaroxaban calibrator and control [Diagnostica Stago], Technochrom anti-Xa and Technoview rivaroxaban calibrator and control [Technoclone]) are now commercially available for clinical use. These assays differ from the INR test and other clotting tests that have been used to monitor traditional anticoagulant agents in that the results are expressed as rivaroxaban concentrations $(\mu \mathrm{g} / \mathrm{l})$.

The perioperative management of patients receiving anticoagulants is an important issue, although guidelines on this are scarce. The principles of when to interrupt and resume rivaroxaban are based on the relatively short half-life, rapid onset of action and dual route of elimination of rivaroxaban [50,51]. The current consensus is that the last dose of rivaroxaban should be taken not less than 24 hours before elective surgery [52], and the manufacturer recommends resumption of rivaroxaban 6-10 hours after surgery, provided haemostasis has been established [3].

Based on the consistent efficacy and safety profiles demonstrated in the large-scale phase III clinical trial programme, fixed-dose regimens of rivaroxaban have been approved for clinical use in several indications. Routine measurement of rivaroxaban plasma levels or its pharmacodynamic effects is not required or recommended. Clinicians should adhere to the regulatory recommendations or the label, particularly in patients or clinical situations associated with an increased risk of bleeding. At present, physicians have many questions on

Table 3 Suitable laboratory tests for rivaroxaban and clinical situations

\begin{tabular}{|c|c|}
\hline $\begin{array}{l}\text { Chromogenic anti-Factor } \\
\text { Xa assay } \\
\text { (with rivaroxaban calibrators) }\end{array}$ & $\begin{array}{l}\text { Prothrombin time test } \\
\text { (with rivaroxaban-sensitive } \\
\text { reagent) }\end{array}$ \\
\hline $\begin{array}{l}\text { - Acute renal failure } \\
\text { - Bleeding complications or } \\
\text { thrombosis during treatment }\end{array}$ & \multirow[t]{8}{*}{$\begin{array}{l}\text { - Emergency situations when an } \\
\text { anti-Factor Xa assay is not available }\end{array}$} \\
\hline $\begin{array}{l}\text { - Emergency situations } \\
\text { (if available in time): }\end{array}$ & \\
\hline Prior to urgent surgery & \\
\hline Life-threatening bleeding & \\
\hline $\begin{array}{l}\text { Stroke (if fibrinolytic } \\
\text { treatment indicated) }\end{array}$ & \\
\hline $\begin{array}{l}\text { Acute percutaneous } \\
\text { coronary intervention } \\
\text { (if heparin bolus indicated) }\end{array}$ & \\
\hline - Overdose & \\
\hline $\begin{array}{l}\text { - Suspected accumulation } \\
\text { of drug }\end{array}$ & \\
\hline
\end{tabular}


the practical aspects of the use of target-specific oral anticoagulants in clinical practice [53], and detailed guidelines are lacking. For example, there is concern among clinicians about switching between anticoagulants and reversing anticoagulant effects; therefore, more recommendations are needed, although the respective labels of the newer agents provide some guidance on these issues [3-8]. To conclude, the choice of laboratory test for rivaroxaban will depend on the clinical situation: if a qualitative assessment of the presence of rivaroxaban in the blood is needed, the PT test is suitable provided that a rivaroxaban-sensitive reagent is used, whereas if a quantitative measurement of plasma rivaroxaban is required, an anti-Factor $\mathrm{Xa}$ chromogenic assay in tandem with rivaroxaban calibrators and controls with results expressed as rivaroxaban concentration $(\mu \mathrm{g} / \mathrm{l})$ can provide accurate results (Table 3). Whichever test is used, interpretation of results must take into account the timing of blood sampling (making reference to the pharmacokinetics of rivaroxaban) and differences in the functionality of the assays (qualitative versus quantitative).

\section{Abbreviations}

AF: Atrial fibrillation; AUC: Area under the concentration-time curve; Bid: Twice daily; $C_{\max }$ : Maximum plasma concentration; $\mathrm{CrCl}$ : Creatinine clearance; $C_{\text {trough: }}$ Minimum plasma concentration; DVT: Deep vein thrombosis; EU: European Union; INR: International normalised ratio; Od: Once daily; PiCT: Prothrombinase-induced clotting time; PT: Prothrombin time; UFH: Unfractionated heparin; US: United States; VKA: Vitamin K antagonist; VTE: Venous thromboembolism.

\section{Competing interests}

CG, LLF and MMS are employees of Biomnis Laboratories Clinical Research; they have no conflicts of interest. GC, YG and JLM are employees of Stago; they have no conflicts of interest. EP is a former employee of and consultant to Bayer HealthCare Pharmaceuticals (the manufacturers of rivaroxaban). TS is an employee of Bayer HealthCare Pharmaceuticals. GR is an employee of Bayer HealthCare AG.

\section{Authors' contributions}

MMS is the lead author. All authors contributed to the writing of the article. All authors read and approved the final manuscript.

\section{Acknowledgements}

The authors would like to acknowledge Li Wan, who provided editorial support with funding from Bayer HealthCare Pharmaceuticals and Janssen Scientific Affairs, LLC.

\section{Author details}

${ }^{1}$ Hôtel-Dieu University Hospital, 1 place du Paris Notre-Dame, 75004 Paris 4ème, Paris, France. ${ }^{2}$ Biomnis Laboratories R \& D, 78 avenue de Verdun, BP 110, 94200 Ivry-sur-Seine, Paris, France. ${ }^{3}$ Diagnostica Stago SA, 125 avenue Louis Roche, P.A.E. Parispace 3, 92230 Gennevilliers, France. ${ }^{4}$ Bayer HealthCare Pharmaceuticals Inc., PO Box 1000, 07045-1000 Montville, NJ, USA. ${ }^{5}$ Bayer HealthCare AG, Aprather Weg 18a, D-42096 Wuppertal, Germany.

\section{Received: 1 March 2013 Accepted: 24 June 2013}

Published: 3 July 2013

\section{References}

1. Ageno W, Gallus AS, Wittkowsky A, Crowther M, Hylek EM, Palareti G: Oral anticoagulant therapy: antithrombotic therapy and prevention of thrombosis, 9th ed: American College of Chest Physicians evidencebased clinical practice guidelines. Chest 2012, 141:e44S-e88S.
2. Garcia DA, Baglin TP, Weitz Jl, Samama MM: Parenteral anticoagulants: antithrombotic therapy and prevention of thrombosis, 9th ed: American College of Chest Physicians evidence-based clinical practice guidelines. Chest 2012, 141:e24S-e43S.

3. Bayer Pharma AG: Xarelto ${ }^{\oplus}$ (rivaroxaban) summary of product characteristics. 2013. http://www.ema.europa.eu/docs/en_GB/document_library/EPAR_-_ Product_Information/human/000944/WC500057108.pdf.

4. Janssen Pharmaceuticals Inc: Xarelto ${ }^{\oplus}$ (rivaroxaban) prescribing information. 2013. http://www.accessdata.fda.gov/drugsatfda_docs/label/ 2013/022406s004lbl.pdf.

5. Boehringer Ingelheim International $\mathrm{GmbH}$ : Pradaxa ${ }^{\circledR}$ (dabigatran etexilate) summary of product characteristics. 2013. http://www.ema.europa.eu/ docs/en_GB/document_library/EPAR_-_Product_Information/human/ 000829/WC500041059.pdf.

6. Boehringer Ingelheim Pharmaceuticals Inc: Pradaxa ${ }^{\circledR}$ (dabigatran etexilate) prescribing ilnformation. 2012. http://www.accessdata.fda.gov/ drugsatfda_docs/label/2012/022512s016lbl.pdf.

7. Bristol-Myers Squibb, Pfizer EEIG: Eliquis ${ }^{\oplus}$ (apixaban) summary of product characteristics. 2012. http://www.ema.europa.eu/docs/en_GB/ document_library/EPAR__Product_Information/human/002148/ WC500107728.pdf.

8. Bristol-Myers Squibb Company, Pfizer Inc: Eliquis ${ }^{\circledast}$ (apixaban) prescribing information. 2012. http://www.accessdata.fda.gov/drugsatfda_docs/label/ 2012/202155s000lbl.pdf.

9. Committee for Medicinal Products for Human Use: Summary of opinion (post authorisation): Xarelto, rivaroxaban. 2013. http://www.ema.europa. eu/docs/en_GB/document_library/Summary_of_opinion/human/000944/ WC500140679.pdf

10. Eisenberg PR, Siegel JE, Abendschein DR, Miletich JP: Importance of factor Xa in determining the procoagulant activity of whole-blood clots. J Clin Invest 1993, 91:1877-1883.

11. Weitz Jl, Hudoba M, Massel D, Maraganore J, Hirsh J: Clot-bound thrombin is protected from inhibition by heparin-antithrombin III but is susceptible to inactivation by antithrombin III-independent inhibitors. J Clin Invest 1990, 86:385-391.

12. Eriksson BI, Quinlan DJ, Eikelboom JW: Novel oral Factor Xa and thrombin inhibitors in the management of thromboembolism. Annu Rev Med 2011, 62:41-57.

13. Perzborn E, Strassburger J, Wilmen A, Pohlmann J, Roehrig S, Schlemmer $\mathrm{KH}$, Straub A: In vitro and in vivo studies of the novel antithrombotic agent BAY 59-7939- an oral, direct Factor Xa inhibitor. J Thromb Haemost 2005, 3:514-521.

14. Samama MM, Guinet C: Laboratory assessment of new anticoagulants. Clin Chem Lab Med 2011, 49:761-772.

15. Kubitza D, Becka M, Voith B, Zuehlsdorf M, Wensing G: Safety, pharmacodynamics, and pharmacokinetics of single doses of BAY 59-7939, an oral, direct Factor Xa inhibitor. Clin Pharmacol Ther 2005, 78:412-421.

16. Perzborn E, Roehrig S, Straub A, Kubitza D, Misselwitz F: The discovery and development of rivaroxaban, an oral, direct Factor Xa inhibitor. Nat Rev Drug Discov 2011, 10:61-75.

17. Mueck W, Eriksson BI, Bauer KA, Borris L, Dahl OE, Fisher WD, Gent M, Haas S, Huisman MV, Kakkar AK, Kälebo P, Kwong LM, Misselwitz F, Turpie AGG: Population pharmacokinetics and pharmacodynamics of rivaroxaban an oral, direct Factor Xa inhibitor - in patients undergoing major orthopaedic surgery. Clin Pharmacokinet 2008, 47:203-216.

18. Xu XS, Moore K, Burton P, Stuyckens K, Mueck W, Rossenu S, Plotnikov A, Gibson M, Vermeulen A: Population pharmacokinetics and pharmacodynamics of rivaroxaban in patients with acute coronary syndromes. Br J Clin Pharmacol 2012, 74:86-97.

19. Mueck W, Lensing AW, Agnelli G, Decousus H, Prandoni P, Misselwitz F: Rivaroxaban: population pharmacokinetic analyses in patients treated for acute deep-vein thrombosis and exposure simulations in patients with atrial fibrillation treated for stroke prevention. Clin Pharmacokinet 2011, 50:675-686.

20. Kubitza D, Becka M, Wensing G, Voith B, Zuehlsdorf M: Safety, pharmacodynamics, and pharmacokinetics of BAY 59-7939 - an oral, direct Factor Xa inhibitor - after multiple dosing in healthy male subjects. Eur J Clin Pharmacol 2005, 61:873-880.

21. Kubitza D, Becka M, Roth A, Mueck W: Dose-escalation study of the pharmacokinetics and pharmacodynamics of rivaroxaban in healthy elderly subjects. Curr Med Res Opin 2008, 24:2757-2765. 
22. Weinz C, Schwarz T, Kubitza D, Mueck W, Lang D: Metabolism and excretion of rivaroxaban, an oral, direct Factor Xa inhibitor, in rats, dogs and humans. Drug Metab Dispos 2009, 37:1056-1064.

23. Mueck W, Becka M, Kubitza D, Voith B, Zuehlsdorf M: Population model of the pharmacokinetics and pharmacodynamics of rivaroxaban-an oral, direct Factor Xa inhibitor-in healthy subjects. Int I Clin Pharmacol Ther 2007, 45:335-344.

24. Samama MM, Martinoli JL, Le Flem L, Guinet C, Plu-Bureau G, Depasse F, Perzborn E: Assessment of laboratory assays to measure rivaroxaban - an oral, direct Factor Xa inhibitor. Thromb Haemost 2010, 103:815-825.

25. Barrett YC, Wang Z, Frost C, Shenker A: Clinical laboratory measurement of direct Factor Xa inhibitors: anti-Xa assay is preferable to prothrombin time assay. Thromb Haemost 2010, 104:1263-1271.

26. Harenberg J, Marx S, Weiss C, Kramer R, Samama M, Schulman S: Report of the subcommittee of control of anticoagulation on the determination of the anticoagulant effects of rivaroxaban. J Thromb Haemost 2012, 10:1433-1436.

27. Sekisui Diagnostics LLC: HepTest. Clotting procedures for the quantitative determination of heparin in plasma and whole blood. 2009. https:// americandiagnostica.com/wp-content/uploads/2011/12/830.pdf.

28. Harder S, Parisius J, Picard-Willems B: Monitoring direct FXa-inhibitors and fondaparinux by Prothrombinase-induced Clotting Time (PiCT): Relation to FXa-activity and influence of assay modifications. Thromb Res 2008, 123:396-403.

29. Graff J, Von Hentig N, Misselwitz F, Kubitza D, Becka M, Breddin HK, Harder $S$ : Effects of the oral, direct Factor Xa inhibitor rivaroxaban on plateletinduced thrombin generation and prothrombinase activity. J Clin Pharmacol 2007, 47:1398-1407.

30. Gerotziafas GT, Elalamy I, Depasse F, Perzborn E, Samama MM: In vitro inhibition of thrombin generation, after tissue factor pathway activation, by the oral, direct Factor Xa inhibitor rivaroxaban. J Thromb Haemost 2007, 5:886-888.

31. Samama MM, Amiral J, Guinet C, Perzborn E, Depasse F: An optimised, rapid chromogenic assay, specific for measuring direct Factor $\mathrm{Xa}$ inhibitors (rivaroxaban) in plasma. Thromb Haemost 2010, 104:1078-1079.

32. Harenberg J, Kramer R, Giese C, Marx S, Weiss C, Wehling M: Determination of rivaroxaban by different Factor Xa specific chromogenic substrate assays: reduction of interassay variability. J Thromb Thrombolysis 2011, 32:267-271.

33. Samama MM, Contant G, Spiro TE, Perzborn E, Guinet C, Gourmelin Y, Le Flem L, Rohde G, Martinoli JL: Evaluation of the anti-Factor Xa chromogenic assay for the measurement of rivaroxaban plasma concentrations using calibrators and controls. Thromb Haemost 2012, 107:379-387.

34. Lindhoff-Last E, Samama MM, Ortel TL, Weitz Jl, Spiro TE: Assays for measuring rivaroxaban: their suitability and limitations. Ther Drug Monit 2010, 32:673-679.

35. Smith SA, Comp PC, Morrissey JH: Phospholipid composition controls thromboplastin sensitivity to individual clotting factors. J Thromb Haemost 2006, 4:820-827.

36. Smith SA, Morrissey $\mathrm{JH}$ : Thromboplastin composition affects the sensitivity of prothrombin time (PT) clotting tests to direct Factor Xa inhibitors. [abstract]. Blood (ASH Annual Meeting Abstracts) 2007, 110:Abstract 928.

37. Siegal DM, Crowther MA: Acute management of bleeding in patients on novel oral anticoagulants. Eur Heart J 2013, 34:489-498.

38. Tripodi A, Chantarangkul V, Guinet C, Samama MM: The International Normalized Ratio calibrated for rivaroxaban has the potential to normalize prothrombin time results for rivaroxaban-treated patients: results of an in vitro study. J Thromb Haemost 2011, 9:226-228.

39. Kluft C: A large effects of rivaroxaban in the PT with specifically Simplastin Excel S may be used for diagnostic purposes [abstract]. Hämostaseologie 2012, 32:A83. Abstract P6-40.

40. Samama MM, Contant G, Spiro TE, Perzborn E, Le Flem L, Guinet C, Gourmelin Y, Martinoli JL: Evaluation of the prothrombin time for measuring rivaroxaban plasma concentrations using calibrators and controls: results of a multicenter field trial. Clin Appl Thromb Hemost 2012, 18:150-158.

41. Kies MS, Posch JJ Jr, Giolma JP, Rubin RN: Hemostatic function in cancer patients. Cancer 1980, 46:831-837.
42. Seifter EJ, Parker Rl, Gralnick HR, Wesley M, DeVita VT Jr, Young RC, Longo $\mathrm{DL}$ : Abnormal coagulation results in patients with Hodgkin's disease. Am J Med 1985, 78:942-950.

43. Thachil J: Relevance of clotting tests in liver disease. Postgrad Med J 2008, 84:177-181.

44. Mani H, Rohde G, Stratmann G, Hesse C, Herth N, Schwers S, Perzborn E, Lindhoff-Last $E$ : Accurate determination of rivaroxaban levels requires different calibrator sets but not addition of antithrombin. Thromb Haemost 2012, 108:191-198.

45. Asmis LM, Alberio L, Angelillo-Scherrer A, Korte W, Mendez A, Reber G, Seifert B, Stricker H, Tsakiris DA, Wuillemin WA: Rivaroxaban: quantification by anti-FXa assay and influence on coagulation tests: a study in 9 Swiss laboratories. Thromb Res 2012, 129:492-498.

46. Mueck W, Borris LC, Dahl OE, Haas S, Huisman MV, Kakkar AK, Kälebo P, Muelhofer E, Misselwitz F, Eriksson Bl: Population pharmacokinetics and pharmacodynamics of once- and twice-daily rivaroxaban for the prevention of venous thromboembolism in patients undergoing total hip replacement. Thromb Haemost 2008, 100:453-461.

47. Eikelboom JW, Weitz Jl: New anticoagulants. Circulation 2010, 121:1523-1532.

48. Bounameaux H, Reber G: New oral antithrombotics: a need for laboratory monitoring. Against. J Thromb Haemost 2010, 8:627-630.

49. Harenberg J, Du S, Kramer S, Giese C, Schulze A, Weiss C, Kramer R: Novel methods for assessing oral direct factor $\mathrm{Xa}$ and thrombin inhibitors: use of point-of-care testing and urine samples. Semin Thromb Hemost 2013, 39:66-71.

50. Schulman S, Crowther MA: How I treat with anticoagulants in 2012: new and old anticoagulants, and when and how to switch. Blood 2012 119:3016-3023.

51. Ortel TL: Perioperative management of patients on chronic antithrombotic therapy. Blood 2012, 120:4699-4705.

52. Turpie AGG, Kreutz R, Llau J, Norrving B, Haas S: Management consensus guidance for the use of rivaroxaban - an oral, direct factor Xa inhibitor. Thromb Haemost 2012, 108:876-886.

53. Huisman MV, Lip GYH, Diener HC, Brueckmann M, van Ryn J, Clemens A: Dabigatran etexilate for stroke prevention in patients with atrial fibrillation: resolving uncertainties in routine practice. Thromb Haemost 2012, 107:838-847

doi:10.1186/1477-9560-11-11

Cite this article as: Samama et al.: Laboratory assessment of rivaroxaban: a review. Thrombosis Journal 2013 11:11.

\section{Submit your next manuscript to BioMed Central and take full advantage of:}

- Convenient online submission

- Thorough peer review

- No space constraints or color figure charges

- Immediate publication on acceptance

- Inclusion in PubMed, CAS, Scopus and Google Scholar

- Research which is freely available for redistribution 